\title{
DOCUMENTOS
}

\section{Calidad y cirugía laparoscópica}

\author{
Prof. Dr. XABIER DE ARETXABALA U., ${ }^{1,2}$ \\ 1 Departamento de Cirugía Hospital Clínico Universidad de Chile. \\ 2 Servicio de Cirugía Clínica Alemana. \\ Santiago, Chile.
}

\section{Perfomance improvement in laparoscopy}

Desde la introducción del concepto calidad aplicado a la atención de salud, por parte del American College of Surgeons en la década de los cincuenta, éste se ha ido implantando en el mundo entero de manera progresiva. En Chile, el concepto de calidad en atención médica está ya implícito en la nueva reforma de salud constituyendo de hecho una de las garantías del programa de Garantías Explícitas en Salud (GES). De este modo, junto con garantizar entre otras cosas la oportunidad y el financiamiento de la atención, el GES exige que la calidad de la atención sea otorgada conforme a estándares previamente establecidos. Así, términos tales como, autorización, acreditación y seguridad en la atención comienzan a ser familiares en la práctica médica diaria.

Al revisar las normas sobre acreditación publicadas por el Ministerio de Salud Pública, se observa que la atención médica debe ser entregada de manera planificada y basada en protocolos, como una forma de garantizar la calidad de atención evitando diferencias en la manera en que dicha atención es administrada. La realización entonces, de prácticas quirúrgicas habituales como podrían ser la colecistectomía o la apendicectomía, deben efectuarse basadas en normas claras y reproducibles de modo transversal, independiente del tipo de establecimiento en que ésta es llevada a cabo o del cirujano que la realiza.

Conjuntamente con la existencia de protocolos de atención, se hace necesario conocer de manera objetiva los resultados obtenidos. Para esto, deben llevarse indicadores tales como: mortalidad post operatoria, morbilidad asociada al procedimiento, días de estada, dolor posterior al procedimiento, entre otros. De acuerdo a la presente reforma de salud actualmente en vigencia, esta forma de llevar a cabo la atención de salud será exigida a todos los centros asistenciales que pretendan atender pacientes beneficiarios del GES. Sin lugar a dudas, la puesta en práctica de lo anterior permitiría garantizar la calidad y seguridad de determinados procedimientos y de este modo entregar a la población una atención conforme a estándares previamente conocidos

La introducción de la cirugía laparoscópica, significó un cambio radical en la manera en que se efectuaba la cirugía. Previo a su aparición, los cambios asociados a la técnica quirúrgica abierta fueron menores y más bien relacionados al diagnóstico y a los métodos de apoyo del post operatorio, pero a grandes rasgos, la técnica en sí no sufría de cambios fundamentales. Desde la aparición de la cirugía laparoscópica, los cambios en la aplicabilidad de la laparoscopia han sido incesantes, incluso muchas veces sin el tiempo necesario para evaluarlos de manera objetiva. En la actualidad no existe prácticamente, procedimiento quirúrgico que no pueda llevarse a cabo vía laparoscópica. No obstante la

* Recibido el 3 de Julio de 2009 y aceptado para publicación el 12 de Agosto de 2009.

Correspondencia: Dr. Xabier de Aretxabala U.

Vitacura 5951, Santiago, Chile.

E-mail: xdearetxabala@alemana.cl 
aplicación de muchas de estas técnicas, ha sido efectuada sin el tiempo ni el análisis necesario como para conocer verdaderamente sus ventajas y desventajas comparada con los métodos tradicionales. Con la excepción del manejo laparoscópico del cáncer de colon, enfermedad en la que sí se realizó un profundo estudio y que permitió conocer sus resultados y compararlo con los métodos tradicionales, esto no ha ocurrido en muchos procedimientos, los que son aceptados sin un previo análisis.

Lamentablemente, la necesidad de recolectar un alto número de casos como también de poseer un largo seguimiento, dificulta la factibilidad de evaluar objetivamente estos nuevos procedimientos. ¿Qué nos lleva a modificar tan drasticamente los paradigmas en los cuales fuimos formados? ¿Qué presión es la que nos hace cambiar? Recientemente, observamos la irrupción de una nueva técnica tan revolucionaria como la laparoscopia pero con menores indicadores de seguridad: "La cirugía a través de orificios naturales". Tan fuerte fue su lanzamiento, que incluso fueron creadas sociedades científicas previas a que este procedimiento se llevara a cabo.

La presión ejercida por la industria relacionada a este tipo de insumos, posee una gran cuota de responsabilidad en la aceptación de dichas técnicas por parte del médico. En el caso de la cirugía a través de orificios naturales, fue tan obvia la falta de un desarrollo tecnológico adecuado, que nunca pudieron salvarse aspectos técnicos básicos, lo que determinó el abandono momentáneo de ella. Debido posiblemente a lo anterior, aparece una nueva modificación a la técnica laparoscópica, basada en la realización de la cirugía mediante una incisión única. Esta nueva técnica, más demandante que la laparoscopia original se basa en el cambio de un campo quirúrgico triangular a uno basado en campos paralelos, hecho que requiere necesariamente de un cambio en la concepción geométrica empleada normalmente en la cirugía laparoscópica tradicional.

Lo que debemos preguntarnos es ¿qué nos lleva a cambiar tan radicalmente nuestra forma de trabajo?; ¿Existe realmente la sensación de un cambio positivo en la percepción por parte del paciente, hacia esta nueva técnica?; ¿Cuán fuerte es el estímulo de la industria hacia la adopción de este nuevo método?; ¿Constituye acaso un factor más bien de diferenciación frente a una competencia cada vez más difícil y homogénea?; ¿Son homologables sus resultados con las técnicas tradicionales?

Frente a este nuevo paradigma, caracterizado por la presencia permanente de cambios en la forma en que nuestros pacientes son manejados, los sistemas de calidad de atención de cada institución deberán desarrollar sistemas de monitoreo que permitan evaluar objetivamente cada una de las diferentes técnicas que se introducen. Aspectos como, curva de aprendizaje de cada técnica, complicaciones asociadas, dificultades técnicas y costo efectividad, deberán ser evaluados por comités idóneos que cumplan la difícil labor de favorecer el desarrollo e introducción de determinadas técnicas por una parte, pero al mismo tiempo, de realizar la evaluación objetiva de cada una de ellas.

Este es el nuevo escenario, un mundo en el que la presión de la industria y del medio será incesante. La industria reconoce al área médica como un sector de enorme interés, un mercado creciente debido tanto al envejecimiento de la población como al mayor ingreso per cápita de países como el nuestro. Por otra parte, la población posee un mayor grado de información, lo que no significa necesariamente poseer un mayor conocimiento.

Debemos organizarnos con el fin de llenar este espacio, tendiente a evaluar el verdadero significado de cada una de las nuevas técnicas introducidas. 